\title{
Breve recorrido por la literatura española del siglo XIX De los románticos hasta la Generación del 98
}

\author{
Aline Kelly Vieira Hernández
}

\begin{abstract}
Resumo
No século XIX, o homem europeu encontra-se inflamado pelas ideias e sentimentos de liberdade, igualdade e fraternidade pregados pela Revolução francesa. Na Espanha, essas ideias e sentimentos são potencializados pela derrota das forças napoleônicas durante a Guerra de Independência espanhola. Toda essa gama de fortes emoções está plasmada na literatura da primeira metade do século. O Romantismo espanhol reflete todo esse sentimento de rebeldia, nacionalismo e necessidade de exaltação dos sentimentos, aliado ao desejo de viver intensamente. $\mathrm{Na}$ segunda metade do século, o Realismo espanhol surge como contraponto às ideias românticas. $O$ Realismo apresenta-se como forma de observação da sociedade e seus costumes. Segundo os realistas, era preciso retratar a vida da forma como ela realmente acontece e não de maneira fantasiosa. Ao final do século, como uma maneira de reagir ao sentimento de decadência que se proliferava na Espanha, causado pelo chamado "Desastre do 98", surge a "Geração do 98", formada por um grupo de jovens escritores espanhóis preocupados pelo futuro e rumo que tomaria sua nação. No presente trabalho, temos como objetivo oferecer um panorama geral da literatura espanhola do século XIX. Não podendo colocar no trabalho todos os autores e obras deste século, tomamos como base alguns dos principais representantes de cada época e movimento literário. Os resultados deste trabalho destinam-se a colaborar em sua medida para os estudos literários sobre a literatura espanhola do século XIX.
\end{abstract}

Palavras-chave: Literatura espanhola; Século XIX; Panorama geral.

\section{Resumo}

En el siglo XIX, el hombre europeo está inflamado por las ideas y sentimientos de libertad, igualdad y fraternidad pregonados por la Revolución francesa. En España, esas ideas y sentimientos están potencializados por la derrota de las fuerzas napoleónicas durante la Guerra de Independencia española. Toda esa variedad de fuertes emociones se refleja en la literatura de la primera mitad de siglo. El Romanticismo español revela todos esos sentimientos de rebeldía, nacionalismo y necesidad de exaltación de los sentimientos, unidos al deseo de vivir intensamente. En la segunda mitad del siglo, surge el Realismo español oponiéndose a las ideas románticas. El Realismo viene como una forma de observación de la sociedad y sus 
costumbres. Según los realistas, era imprescindible retratar la vida como realmente ocurre y no de manera fantasiosa. Al final del siglo, como una forma de reaccionar ante el sentimiento de decadencia y desencanto que se prolifera en España, causado por el llamado "Desastre del 98", surge la "Generación del 98", formada por un grupo de jóvenes escritores españoles preocupados por el futuro y el rumbo que tomaría su nación. En el presente trabajo tenemos como objetivo ofrecer un panorama general de la literatura española del siglo XIX. No pudiendo poner en el trabajo todos los autores y obras de este siglo, tomamos como base algunos de los principales representantes de cada época y movimiento literario. Los resultados de este trabajo destinan se a colaborar para los estudios literarios sobre la literatura española del siglo XIX.

Palabras clave: Literatura española; Siglo XIX; Panorama general.

\section{INTRODUCCIÓN}

El en siglo XIX la humanidad pasa por profundos cambios. Las guerras de Independencia hacen con que el hombre del XIX mire la vida desde otra perspectiva. A partir de ahora el hombre anhela la libertad y la independencia. Surgen los movimientos rebeldes, el rechazo a las reglas, al régimen político. Surgen los nacionalismos, la exaltación de los sentimientos ante la razón. La revolución industrial, empezada a finales del siglo XVIII, proporciona el avance tecnológico a diversos países, favoreciendo el desarrollo industrial y económico con bases en el trabajo del proletario. La sociedad está dividida entonces por clases sociales. Surge la Burguesía, que detiene el poder económico e político, desplazando así, la nobleza de su papel de poderío. Como consecuencia, las tensiones sociales originarias de los cambios de poder se reflejan en la política. Todos esos cambios también generaron otra forma de pensar la literatura. Es dentro de este contexto de deseo de libertad que surgen movimientos como el Romanticismo y el Realismo.

El Romanticismo viene como una respuesta al Neoclasicismo tan lleno de reglas y pensamientos razonables. Los románticos defienden la libertad creadora, la exaltación del sentimiento y de la naturaleza. Al hombre romántico le interesa vivir con intensidad. Los autores románticos solían llevar una vida muy intensa, bohemia y, a veces, muy corta. Sin embargo, en la segunda mitad del siglo, surge el Realismo, un movimiento literario que viene para contrastar con los "colores" demasiado fantasiosos y subjetivistas del Romanticismo. Los escritores realistas se basaban en la observación de la sociedad para componer sus obras, reproduciendo lo más fielmente posible el producto de sus observaciones. El siglo se acaba con el surgimiento de un grupo de escritores, llenos de inquietudes existenciales, denominado por Azorín la "Generación del 98”. Este grupo de escritores se preocupa sobretodo del rumbo decadente y desolador que sigue España tras lo que se llamó el "Desastre del 98”.

\section{El Romanticismo Español}


En Europa el Romanticismo tiene inicio con las influencias de Goethe, Walter Scott e ideas de Schlegel. En España el Romanticismo penetra sobre todo por Andalucía y Cataluña. La vuelta de los intelectuales que tuvieron que exiliarse por la persecución de Fernando VII y después de su muerte en 1833 empiezan a volver poco a poco, la defensa del teatro del siglo XVII por Nicolás Böhl de Faber, apoyado en las ideas de Schlegel y la publicación de la revista El europeu (Barcelona), que defendía las ideas románticas, fueron las principales puertas de entrada del Romanticismo en España.

\subsection{El teatro Español del Romanticismo}

En 1834, Martínez de La Rosa introduce en España el drama romántico con La conjuración de Venecia, pero es solo en 1835 que el Romanticismo triunfa en el teatro español, con el estreno de la obra en prosa, Don Álvaro o la fuerza del sino, del Duque de Rivas. Llena de elementos puramente románticos, tuvo un gran éxito, pero también produjo un gran choque en la sociedad española cristiana de la época.

La obra cuenta la historia del amor prohibido de Don Álvaro y Doña Leonor. Don Álvaro, al intentar huir por la noche con su amada es sorprendido por el Marqués de Calatrava (padre de Doña Leonor) y por accidente lo mata. Doña Leonor se encierra en un convento. Don Álvaro cambia de identidad por tres veces para escaparse de la venganza de los hermanos de Leonor, que juraron matarle y acaban muriendo por la espada de Don Álvaro. Doña Leonor muere por las manos de su hermano y Don Álvaro se suicida llamando por el infierno.

DON ÁLVARO. Infierno, abre tu boca y trágame. Húndase el cielo, perezca la raza humana; exterminio, destrucción... (Sube a lo más alto del monte y se precipita.)

EL P. GUARDIÁN Y LOS FRAILES. (Aterrados y en actitudes diversas.) ¡Misericordia, Señor! ¡Misericordia! (RIVAS, 1835, p.70)

Otra pieza teatral de gran éxito, fue la obra en verso de José de Zorrilla, Don Juan Tenorio, cuyo estreno se dio en 1844. Para escribir Don Juan Tenorio, Zorrila toma como inspiración el personaje principal Don Juan de El burlador de Sevilla o el convidado de piedra de Tirso de Molina, es decir, es el mismo Don Juan, pero con otro ropaje. Don Juan es un conquistador y amoral, se burla de las mujeres hasta que conoce Luís Mejías, un capitán y también conquistador con quien hace una aposta y acaba por conocer a Doña Inés (típica mujer romántica) a través de quien encuentra la salvación después de la muerte.

DON JUAN, LA ESTATUA DE DON GONZALO DOÑA INÉS, SOMBRAS, etc.

D. ${ }^{a}$ INÉS. ¡No! Heme ya aquí, don Juan mi mano asegura esta mano que a la altura tendió tu contrito afán, y Dios perdona a don Juan al pie de la sepultura. D. JUAN. ¡Dios clemente! ¡Doña Inés!

D. ${ }^{a}$ INÉS. Fantasmas, desvaneceos: su fe nos salva..., volveos a vuestros sepulcros, 
pues. La voluntad de Dios es de mi alma con la amargura purifiqué su alma impura, y Dios concedió a mi afán la salvación de don Juan al pie de la sepultura. (ZORRILLA, 1844, p.177)

El teatro romántico quizá alcanzó tanto éxito por la carga de misterio que posee. Elementos como la lluvia, la noche, ambientes oscuros, venganzas, amores imposibles y hasta de ultratumba despiertan en el público un deseo de apartarse de la realidad para penetrar en un mundo desconocido. En general, la trama romántica transcurre de noche y el protagonista tiene un destino misterioso.

\subsection{LA POESÍA ROMÁNTICA ESPAÑOLA}

En la poesía española del Romanticismo, los poetas se dejan llevar por los sentimientos y por la melancolía. Toman la poesía como una protesta a las normas sociales o contra la propia vida. Se inspiran en temas exóticos y exaltan sentimientos como la belleza y la soledad. De acuerdo con sus emociones, cambian el metro combinando versos y estrofas e inventando nuevas, de modo a ajustarse a las distintas fases por las que pasan sus emociones.

José de Espronceda, uno de los principales poetas del Romanticismo, escribió poesías como La canción del pirata (pirata como símbolo de la libertad), Canción del corsario, El mendigo, A Jarifa en una orgia. Además de escribir el poema narrativo El estudiante de Salamanca, que cuenta la historia de Don Felix de Montemar, que de la misma manera que Don Juan, es un conquistador sin carácter, que se burla de las mujeres y al final se casa con una difunta en una ceremonia funesta en el cementerio. La obra está compuesta por cerca de dos mil versos polimétricos y rellenada de elementos románticos: ambientes lúgubres, sombras, amores de ultratumba, misterio y oscuridad.

\footnotetext{
¡Que era pública voz, que llanto arranca

del pecho pecador y empedernido, que en forma de mujer y en una blanca túnica misteriosa revestido, aquella noche el diablo a Salamanca había en fin por Montemar venido!... Y si, lector, dijerdes ser comento, como me lo contaron, te lo cuento. (ESPRONCEDA, 1840, p.75)
}

Otro escritor muy importante y muy significativo de la época romántica española, fue Mariano José de Larra. Era el máximo exponente romántico de España junto con Zorrilla. Tuvo una vida de amarguras, muy intensa y con una muerte muy precoz a los veintiocho años. Larra siguió el género periodístico, sobre todo, pero también escribió la novela histórica El 
doncel de D. Enrique el doliente y los dramas históricos Macías (historia de un trovador medieval) y El conde Fernán González y la exención de Castilla. Su carácter muchas veces áspero le sirvió para escribir brillantes artículos costumbristas como El castellano viejo, crítica al modo mal educado de los españoles, Los toros - donde critica las tradiciones brutales y Vuelva usted mañana - crítica a la burocracia española. Escribió artículos de crítica literaria, en que expresaba su gusto estético, y artículos de política como La alabanza o que me prohíban este, El mundo todo es máscaras Todo el año es carnaval, Un reo de muerte, entre otros. Sin embargo, en sus artículos La nochebuena y El día de difuntos, es donde refleja su gran desengaño y amargura ante la vida.

A pesar de muy intenso, el Romanticismo español tuvo corta duración. Desde el estreno de D. Álvaro y la fuerza del sino (1835) y el surgimiento del Realismo (1850), se transcurren solamente quince años. El Realismo surge como una respuesta al modo soñador y romántico de ver la vida. Según los realistas, era necesario mirar la vida desde una perspectiva más real.

\section{El Realismo Español}

El Realismo, movimiento literario de la segunda mitad del siglo XIX, tenía como propuesta reflejar la realidad de la sociedad como una forma de percibir la vida cotidiana de la manera real, sin las subjetividades o fantasías tan características del Romanticismo. Surge como una especie de reacción a los excesos de la imaginación romántica.

El término Realismo alude a la semejanza que existe entre la creación artística y el entorno. Desde Aristóteles, una larga tradición de preceptistas y creadores ha concebido el arte como imitación de las acciones humanas y de los fenómenos de la naturaleza. En la conformación de una obra literaria realista hay dos pasos esenciales: el conocimiento del mundo que se quiere reflejar y la elección de los medios estilísticos adecuados para provocar en el receptor la impresión de que se halla ante su ámbito cotidiano. (JIMÉNEZ; CÁCERES, 2007, p.223)

En España, el Realismo tardó en llegar por varios motivos, tales como: el escaso desarrollo económico e industrial del país y los conflictos sociales constantes (movimientos revolucionarios: socialismo y anarquismo, que hacían frente a la burguesía). En el campo cultural había el conflicto de "las dos Españas" entre tradicionalistas, que defendían una España antiliberal, nacional y católica, y progresistas que, influidos por los ideales franceses de igualdad y libertad, deseaban una España liberal y de libre expresión, incluso religiosa.

La obra que marca el inicio del Realismo español es La gaviota de Fernán Caballero (que en realidad es el seudónimo de Cecilia Böhl de Faber). La historia está ambientada en Andalucía. La gaviota es el apodo de una cantante andaluza, así llamada por poseer una bella voz. La obra retrata las costumbres andaluzas y su folclore. Algunos críticos coinciden al decir 
que La gaviota tiene un fondo demasiado moralizante y personajes muy marcados (buenos y malos).

El género inaugurado por el Realismo fue la novela de tesis, donde el autor se vale de sus personajes para expresar sus ideologías personales. Esto queda muy claro en la importante obra La Regenta de Leopoldo Alas, “Clarín”. En ella Clarín retrata su pensamiento sobre la sociedad de Oviedo (llamada Vetusta en la trama) y sus costumbres. Deja esto estampado al principio al comentar sobre la costumbre de dormir "después de comer la olla podrida".

La heroica ciudad dormía la siesta. El viento Sur, caliente y perezoso, empujaba las nubes blanquecinas que se rasgaban al correr hacia el Norte. En las calles no había más ruido que el rumor estridente de los remolinos de polvo, trapos, pajas y papeles que iban de arroyo en arroyo, de acera en acera, de esquina en esquina revolando y persiguiéndose, como mariposas que se buscan y huyen y que el aire envuelve en sus pliegues invisibles. Cual turbas de pilluelos, aquellas migajas de la basura, aquellas sobras de todo se juntaban en un montón, parábanse como dormidas un momento y brincaban de nuevo sobresaltadas, dispersándose, trepando unas por las paredes hasta los cristales temblorosos de los faroles, otras hasta los carteles de papel mal pegado a las esquinas, y había pluma que llegaba a un tercer piso, y arenilla que se incrustaba para días, o para años, en la vidriera de un escaparate, agarrada a un plomo. Vetusta, la muy noble y leal ciudad, corte en lejano siglo, hacía la digestión del cocido y de la olla podrida, y descansaba oyendo entre sueños el monótono y familiar zumbido de la campana de coro, que retumbaba allá en lo alto de la esbelta torre en la Santa Basílica. (ALAS Clarín, 1845, p.13)

Benito Pérez Galdós retrata, por excelencia, los hechos de la realidad a través de la observación, reflejando todo su análisis en sus obras. Sus novelas de primera época, todas hasta La desheredada (1881), las novelas contemporáneas, entre ellas Fortunata y Jacinta (1887), y los Episodios Nacionales (1873-1912), obra de cuarenta y seis novelas, donde Galdós se propuso a contar la historia de España en el siglo XIX desde Trafalgar (1805) hasta La Restauración (1875), reflejan el retrato de una época y su mirada hacia la sociedad madrileña del XIX.

Benito Pérez Galdós. Episodios nacionales

\author{
$1^{a}$ Serie \\ 1873.- "Trafalgar" \\ 1873.- "La corte de Carlos IV" \\ 1873.- "El 19 de marzo y el 2 de mayo" \\ 1873.- "Bailén" \\ 1874.- "Napoleón en Chamartín” \\ 1874.- "Zaragoza" \\ 1874.- "Gerona" \\ 1874.- "Cádiz" \\ 1874.- "Juan Martín el Empecinado"
}

1875.- "La batalla de los Arapiles"

$2^{a}$ Serie

1875.- "El equipaje del rey José"

1875.- "Memorias de un cortesano de 1815"

1876.- "La segunda casaca"

1876.- "El Grande Oriente"

1876.- "7 de julio"

1877.- "Los cien mil hijos de San Luis"

1877.- "El terror de 1824" 
1878.- "Un voluntario realista"

1879.- "Los apostólicos"

1879.- "Un faccioso más y algunos frailes menos"

\section{$3^{a}$ Serie}

1898.- "Zumalacárregui"

1898.- "Mendizábal"

1898.- "De Oñate a la Granja"

1899.- "Luchana"

1899.- "La campaña del maestrazgo"

1899.- "La estafeta romántica"

1899.- "Vergara"

1900.- "Montes de Oca"

1900.- "Los Ayacuchos"

1900.- "Bodas reales"

\section{$4^{a}$ Serie}

1902.- "Las tormentas del 48"

1902.- "Narváez"

1903.- "Los duendes de la camarilla"

1904.- "La revolución de julio"

1904.- "O’Donnell”
1905.- "Aita-Tettauen"

1905.- "Carlos VI en la Rápita"

1906.- "La vuelta al mundo en la Numancia"

1906.- "Prim"

1907.- "La de los tristes destinos"

$5^{a}$ Serie

1908.- "España sin rey"

1909.- "España trágica"

1910.- "Amadeo I"

1911.- "La primera República"

1911.- "De Cartago a Sagunto"

1912.- "Cánovas"

En contra todo ese realismo tan duro, encontramos la figura elegante y refinada de Juan Valera, que defendía la belleza de las formas y rechaza la novela de tesis. Su estilo fino, elegante y culto, le hacía pensar en Realismo idealizado, pensaba que, si la realidad es tan dura y cruel, ¿porque no hacer novelas distintas de la realidad? Le gustaba escribir historias bonitas y que reflejasen su refinamiento. Autor de obras como Juanita la larga y Pepita Jiménez, es más dado a las novelas que resaltan los rasgos psicológicos de los personajes.

Valera constituye un caso aparte en la producción novelística del siglo. Su carrera literaria se inició dentro de la órbita del Romanticismo, pero pronto su temperamento reflexivo y sereno, le hizo repudiar los excesos imaginativos y el desbordamiento sentimental de aquella generación. Al mismo tiempo, una aguda intuición de los valores estéticos le inclinó a considerar equivocadas las tendencias de la época. Partidario del arte por el arte, le molestaba la novela de "tesis" y veía un puro error en el afán de exactitud realista. (GARCÍA, 2006, p. 556)

El Naturalismo formó parte del Realismo, pero en España no tuvo mucho éxito como en el resto de Europa. El Naturalismo intentaba enseñar dentro de la novela realista la parte más científica y material de algunos hechos. Emilia Pardo Bazán, fue el nombre del Naturalismo en España, escribió una colección de artículos sobre el movimiento, bajo el título de La cuestión palpitante, donde expresa sus ideas y oposiciones hacia el movimiento naturalista. En ellos Pardo Bazán reconoce el valor de Émile Zola - padre del Naturalismo como escritor, pero no compartía del determinismo y del materialismo del movimiento 
naturalista. El propio Zola no entendía como una mujer cristiana podía ser la defensora del movimiento naturalista en España. Sus novelas Los pazos de Ulloa y La madre naturaleza, ambientadas en el mundo rural de Galicia, muestran sus claras influencias naturalistas en su gusto por ambientes rudos, crudos y de pasiones violentas.

\section{Los ALbores Del Modernismo}

A finales del siglo XIX la América española sufre grandes cambios sociales y económicos. A partir de las independencias de las naciones hispanoamericanas y la desvinculación de España, surge el deseo y la necesidad de construirse una identidad cultural propia de América. En medio a todo eso surgen las primeras ideas modernistas. La palabra Modernismo surge en tono despectivo contra aquellos que querían romper con el Realismo. Surge como un rechazo al materialismo y al sentido utilitario de la burguesía. Según Octavio Paz:

El modernismo fue la respuesta al Positivismo, la crítica de la sensibilidad y el corazón — también de los nervios - al empirismo y el cientismo positivista. En este sentido su función histórica fue semejante a la de la reacción romántica en el alba del siglo XIX. El modernismo fue nuestro verdadero romanticismo y, como en el caso del simbolismo francés, su versión no fue una repetición, sino una metáfora: otro romanticismo. (...) el positivismo latinoamericano, más que un método científico, fue una ideología, una creencia. Su influencia sobre el desarrollo de la ciencia en nuestros países fue muchísimo menor que su imperio sobre las mentes y las sensibilidades de los grupos intelectuales. (PAZ, 1974. p. 160)

Rubén Darío fue el nombre más significativo del movimiento modernista. Con su libro Azul... (1880) inaugura lo que sería el movimiento de los colores y de la renovación del lenguaje poético en lengua española. El Modernismo adoptó rasgos del Simbolismo y del Parnasianismo (movimientos que figuran en Francia en la misma época). Del Parnasianismo adoptó la búsqueda por la belleza y la perfección de las formas; del Simbolismo, el ritmo y la musicalidad de los versos. El interés por temas exóticos de lugares lejanos, luces, colores, princesas y el cisne como símbolo de la belleza de las formas, son rasgos predominantes del Modernismo. El "escapismo", fue una de las principales características de este nuevo tipo de estética poética. La poesía "escapista" es una de las herramientas usadas por el autor modernista para transportar al lector a otras dimensiones, demostrando que la vida tiene un significado mayor, que ultrapasa el material y el palpable.

¿Hay en mi sangre alguna gota de sangre de África, de indio chorotega ó nagrandano? Pudiera ser, á despecho de mis manos de marqués: más he aquí que veréis en mis versos, princesas, reyes, cosas imperiales, visiones de países lejanos o imposibles: iqué queréis! Yo detesto mi vida y el tiempo en que me tocó nacer;(...) (DARÍO, 1901, 
La llegada de Rubén Darío a España en 1892 es decisiva para la renovación de la lírica española. Manuel Machado y Juan Ramón Jiménez son algunos de los nombres de poetas españoles que desean una renovación de la poesía.

Los poetas del Modernismo español se sienten "seducidos" por la brillantez y por la sensibilidad de la poesía de Rubén Darío, considerado el gran responsable por la renovación de la poesía en España. El Modernismo no es un movimiento literario que se detiene solo a la poesía del momento. Sus rasgos e ideas renovadoras hacen eco en toda la literatura española de principios del siglo XX.

\section{LA GENERACIÓN DEL 98}

En España, tras el "Desastre del 98" (España en 1898, tras un enfrentamiento con Estados Unidos pierde sus últimas colonias, Cuba, Puerto Rico y Filipinas), surge un grupo de jóvenes escritores anhelantes de una renovación literaria. Miguel de Unamuno, Pio Baroja, Antonio Machado, Maeztu, Azorín, Ángel Ganivet, Valle-Inclán, entre otros, forman parte de una generación de escritores españoles, denominada por Azorín “Generación del 98”, preocupados por la situación y el rumbo del país y por el sentimiento de crisis y decadencia que pasaba España en aquel momento. Los autores, casi de la misma edad, relacionaban se entre ellos y compartían de las mismas inquietudes.

Miguel de Unamuno, por ejemplo, en sus obras hacía largas reflexiones sobre el sentido de la existencia y el destino del hombre, la existencia de Dios y la fe. La naturaleza atormentada de Unamuno se refleja en toda su producción literaria. Obras como Niebla, del sentimiento trágico de la vida (donde expresa la angustia del hombre delante de la realidad de la muerte), muestran con mucha claridad su espíritu inquieto.

La fe en la inmortalidad es irracional. Y, sin embargo, fe, vida y razón se necesitan mutuamente. Ese anhelo vital no es propiamente problema, no puede tomar estado lógico, no puede formularse en proposiciones racionalmente discutibles, pero se nos plantea, como se nos plantea el hambre. Tampoco un lobo que se echa sobre su presa para devorarla, o sobre la loba para fecundarla, puede plantearse racionalmente y como problema lógico su empuje. Razón y fe son dos enemigos que no pueden sostenerse el uno sin el otro. Lo irracional pide ser racionalizado, y la razón sólo puede operar sobre lo irracional. Tienen que apoyarse uno en otro y asociarse. Pero asociarse en lucha, ya que la lucha es un modo de asociación. (UNAMUNO, 2003, p. $322)$

La obra de Ángel Ganivet, como la de Unamuno, está marcada por una intranquilidad espiritual y una incertidumbre sobre los temas transcendentales. Autor del Idearium español, 
era otro espíritu inquieto que dio fin a su propia existencia con solo treinta y tres años. En el Idearium español, Ganivet hace una reflexión filosófica sobre la situación psicológica de los españoles. Fue un gran estudioso e intelectual, pero fue vencido por una gran depresión y por una crisis espiritual que le afligió hasta sus últimos momentos.

Valle-Inclán con su teatro de "esperpento" (grotesco), era duro y áspero criticando severamente la sociedad al deformar la realidad de sus personajes. Es un tipo de teatro que nos presenta un realismo deformado de la sociedad. Un ejemplo es la obra Divinas palabras, en la cual retrata el adulterio de Mari Gaila, una mujer que vive en un pueblo donde la gente le quiere castigar. Se salva al final gracias a las palabras bíblicas proferidas en latín por su marido Pedro Gailo, el sacristán.

PEDRO GAILO ¡Quien sea libre de culpa, tire la primera piedra!

VOCES ¡Consentido!

OTRAS VOCES ¡Castrado!

Las befas levantan sus flámulas, vuelan las piedras y llamean en el aire los brazos. Cóleras y soberbias desatan las lenguas. Pasa el soplo encendido de un verbo popular y judaico.

UNA VIEJA ¡Mengua de hombres!

El sacristán se vuelve con saludo de iglesia, y bizcando los ojos sobre el misal abierto, reza en latín la blanca sentencia.

REZO LATINO DEL SACRISTÁN

Qui sine peccato est vestrum, primus in illan lapidem mittat.

El sacristán entrega a la desnuda la vela apagada y de la mano la conduce a través del atrio, sobre las losas sepulcrales... ¡Milagro del latín! Una emoción religiosa y litúrgica conmueve las conciencias y cambia el sangriento resplandor de los rostros. Las viejas almas infantiles respiran un aroma de vida eterna. No falta quien se esquive con sobresalto y quien aconseje cordura. Las palabras latinas, con su temblor enigmático y litúrgico, vuelan del cielo de los milagros.

SERENÍN DE BRETAL ;Apartémonos de esta danza!

QUINTÍN PINTADO También me voy, que tengo sin guardas el ganado. MILÓN DE LA ARNOYA ¿Y si esto nos trae andar en justicias?

SERENÍN DE BRETAL No trae nada.

MILÓN DE LA ARNOYA ¿Y si trujese?

SERENÍN DE BRETAL ¡Sellar la boca para los civiles, y aguantar mancuerda! Los oros del poniente flotan sobre la quintana. MARI-GAILA, armoniosa y desnuda, pisando descalza sobre las piedras sepulcrales, percibe el ritmo de la vida bajo un velo de lágrimas. Al penetrar en la sombra del pórtico, la enorme cabeza del idiota, coronada de camelias, se le aparece como una cabeza de ángel. Conducida de la mano del marido, la mujer adúltera se acoge al asilo de la iglesia, circundada del áureo y religioso prestigio, que, en aquel mundo milagrero, de almas rudas, intuye el latín ignoto de las DIVINAS PALABRAS.

(VALLE-INCLÁN,1920, p.118)

Otro nombre de gran expresión de la generación del 98 fue Pio Baroja, un gran pesimista, un hombre angustiado, muy influido por Nietzsche y Schopenhauer. Baroja fue un 
inconformista que no creía en Dios, en la vida y tampoco en el hombre, llegando a declarar que creía que el hombre es un animal, dañino y cruel. Sin embargo, tuvo un gran cariño por los seres menos favorecidos o desvalidos. Gran parte de sus personajes son seres marginados y frustrados, pero la dignidad que da a todos ellos le destacan como gran escritor humano y ético. Su manera de escribir es muy natural y espontánea, partiendo de la observación de la vida misma. En El árbol de la ciencia, una de sus obras de mayor expresión, refleja a través del protagonista muchos aspectos de su propia vida, como su inconformismo, su conflicto existencial y sus preocupaciones con el destino de España. Algunas obras de Baroja y de Unamuno son claros antecedentes del existencialismo europeo.

Finalmente, para concluir este siglo tan lleno de bellos frutos y contradicciones, podemos hablar de Antonio Machado y sus poesías tan bellas, en las que expresa su dulzura y a la vez su amargura por perder su amada esposa tan prematuramente.

\author{
(CANTE HONDO) \\ Yo meditaba absorto, devanando \\ los hilos del hastío y la tristeza, \\ cuando llegó a mi oído, \\ por la ventana de mi estancia, abierta \\ a una caliente noche de verano, \\ el plañir de una copia soñolienta, \\ quebrada por los trémolos sombríos \\ de las músicas magas de mi tierra. \\ ... Y era el Amor, como una roja llama... \\ ?Nerviosa mano en la vibrante cuerda \\ ponía un largo suspirar de oro \\ que se trocaba en surtidor de estrellas? \\ ... Y era la Muerte, al hombro la cuchilla, \\ el paso largo, torva y esquelética. \\ ¿Tal cuando yo era niño la soñaba? \\ $Y$ en la guitarra, resonante y trémula, \\ la brusca mano, al golpear, fingía \\ el reposar de un ataúd en tierra. \\ Y era un plañido solitario el soplo \\ que el polvo barre y la ceniza avienta. \\ (MACHADO, 1995, p.105)
}

En su libro Soledades. Galerías. Otros poemas (1899-1907), Machado refleja la influencia sufrida en su poesía por el Modernismo y el Simbolismo. Los temas recurrentes de la obra son la muerte, la melancolía, la soledad y la angustia. 


\section{CONCLUSIÓN}

En este breve y rápido paseo que hicimos por la literatura española del siglo XIX, pudimos ver un poco de la gama de sentimientos manifiestos en las obras por sus autores, ocasionados por las transformaciones sufridas por la sociedad española de entonces. Pudimos darnos cuenta de los grandes cambios de mentalidad a lo largo del siglo motivados por los diversos momentos vividos por la sociedad española de dado siglo. En España, el siglo XIX empieza con la Guerra de Independencia de la cual sale victoriosa. Al principio del XIX, triunfan los sentimientos de rebeldía y revolución, sin embargo, a finales de siglo, con el "Desastre del 98" y el fin del imperio español, abundan los sentimientos de desolación, preocupación y melancolía. Aunque los sentimientos y motivaciones, cambien en cierta medida al principio y a finales del siglo, permanecen en todas las épocas, el deseo de renovación constante de la literatura, la cual tiene como instrumento reflejar con gran belleza los momentos principales de cada siglo, desde el principio hasta el final de los tiempos. 
ALAS, L. La Regenta. Disponible en: $<\underline{\text { ht }}$ tp://www.siruela.com/archivos/frag-

mentos/LaRegentafg.pdf>

CAUDET, F. El parto de la modernidad: la novela española de los siglos XIX y XX. Madrid: Ediciones de la Torre, 2002.

DARIO, R. Prosas profanas y otros poemas. Disponible en: <file:///C:/Users/Aline $\% 20$ Vieira/Downloads/prosas-

profanas-y-otros-poemas.pdf

http://cdigital.dgb.uan-

$\underline{\mathrm{l} m \mathrm{mx} / \mathrm{la} / 1080011102 / 1080011102 . \mathrm{PDF}}>(190$ 1)

ESPRONCEDA, J. El estudiante de Salamanca. Disponible en: $<\underline{\text { ht }}$ tp://www.edu.mec.gub.uy/biblioteca digital/libros/E/Espronceda, $\%$ 20Jose $\% 20 \mathrm{de}^{2} \% 20$ $-\% 20 \mathrm{El} \% 20$ estudiante $\% 20 \mathrm{de} \% 20$ Salamanca.pdf $>$

FERRER, J.; CAÑUELO, S. Historia de la Literatura Universal. Barcelona: Editorial Optima S.L., 2002.

GALDÓS, B. P. Los episodios nacionales. Disponible en: < $\underline{\text { http://www.cervantes.es- }}$ Lbibliotecas documentacion espanol/biografias/rabat benito perez galdos $3 . \mathrm{htm}>$

JIMÉNEZ, F. P.; CÁCERES, M. R. Las épocas de la literatura española. Barcelona: Ariel S.A., 2007.

LOPÉZ, J. G. Historia de la literatura española. Barcelona: Vicens Vives S.A., 2006.

MACHADO, A. Soledades. Galerías. Otros poemas. Madrid: Ediciones Cátedra,1995.

PRADO, J.M; RODRIGO, R. Historia Universal de la Literatura. Navarra: Ediciones Orbis, S.A., 1990.
PAZ, O. Los hijos del limo. Disponible en : $<\underline{\text { https://filosevilla2012.files.wordpress.- }}$ com/2015/09/paz-octavio-los-hijos-dellimo.pdf $>$

RIVAS, A. S. Don Álvaro o la fuerza del sino. Disponible en: < http://biblioteca.org.ar/libros/130526.pdf $>$

SHAW, D. L. Historia de la literatura española Vol.5 El siglo XIX. Traducción de Helena Calsamiglia. Barcelona: Ariel, 1980.

VALLE-INCLÁN, R. Divinas Palabras. Disponible en:

$<$ http://www.edu.xunta.gal/centros/iesvaladares/system/files/Inclan $+\mathrm{Ra}-$ $\underline{\text { mon }+ \text { Del+Valle }+-+ \text { Divinas }+ \text { Palabras.pdf }>}$

ZORRILLA, J. Don Juan Tenorio. Disponible en: $\quad<$ http://www.css.cl/catalogo/pdf/lib014956-.pdf $>$ 